


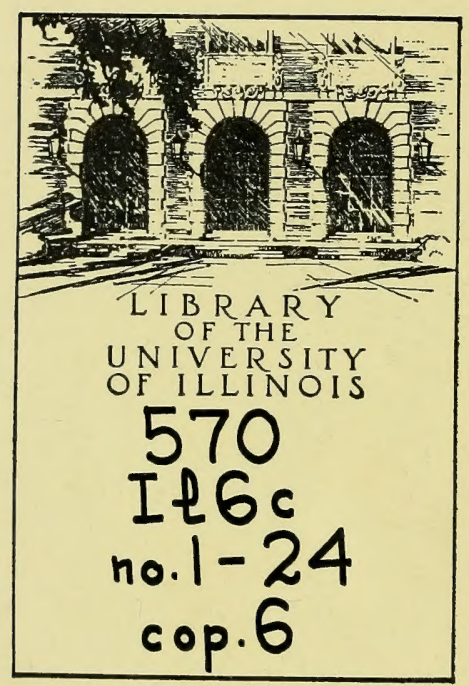

NATURAL HISTORY
SURVEY 
Digitized by the Internet Archive in 2011 with funding from

University of Illinois Urbana-Champaign

http://www.archive.org/details/fruittreeleafrol16flin 



Department of Registration and Education STATE NATURAL HISTORY SURVEY DIVISION Stephen A. Forbes, Chief

Entomological Series

CIRCULAR 9

\section{THE FRUIT TREE LEAF ROLLER AND ITS CONTROL UNDER ILLINOIS CONDITIONS}

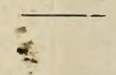

Urbana, Illinois

1926

บ. Of 11น UB. 


\section{SUMMARY}

The fruit tree leaf roller has become abundant and very destructive in certain orchards in western Illinois during the past five years.

Experiments for a control of this insect by the use of poison sprays showed that this method was not practical.

Dormant spraying of the egg masses with a number of miscible oils and home-made lubricating oil emulsions has shown that very satisfactory control can be obtained with an $8 \%$ boiled lubricating oil emulsion made according to the Illinois formula.

Cold-mixed oil emulsions at the same strength also gave excellent control in the experimental work.

More than 1200 acres of apple orchards were sprayed with the boiled lubricating oil emulsion at $8 \%$ strength during the winter of 1924-25. The result of this treatment was an almost complete clean-up of the leaf roller and incidentally a clean-up of San Jose scale in the orchards treated. All of the orchards sprayed in this way bore good crops in 1925 , and no detrimental effect of the spray on the trees, fruit, or foliage could be seen during the growing season.

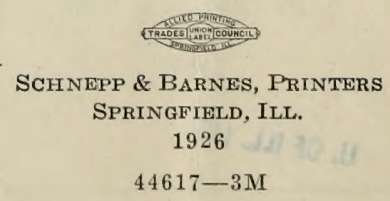


Occasionally some of our native insects which have fed on woodland trees or shrubs become adapted to farming conditions, change their habits slightly and become pests of first-class importance on our farm crops. The fruit tree leaf roller is a good example of such a pest. It has been

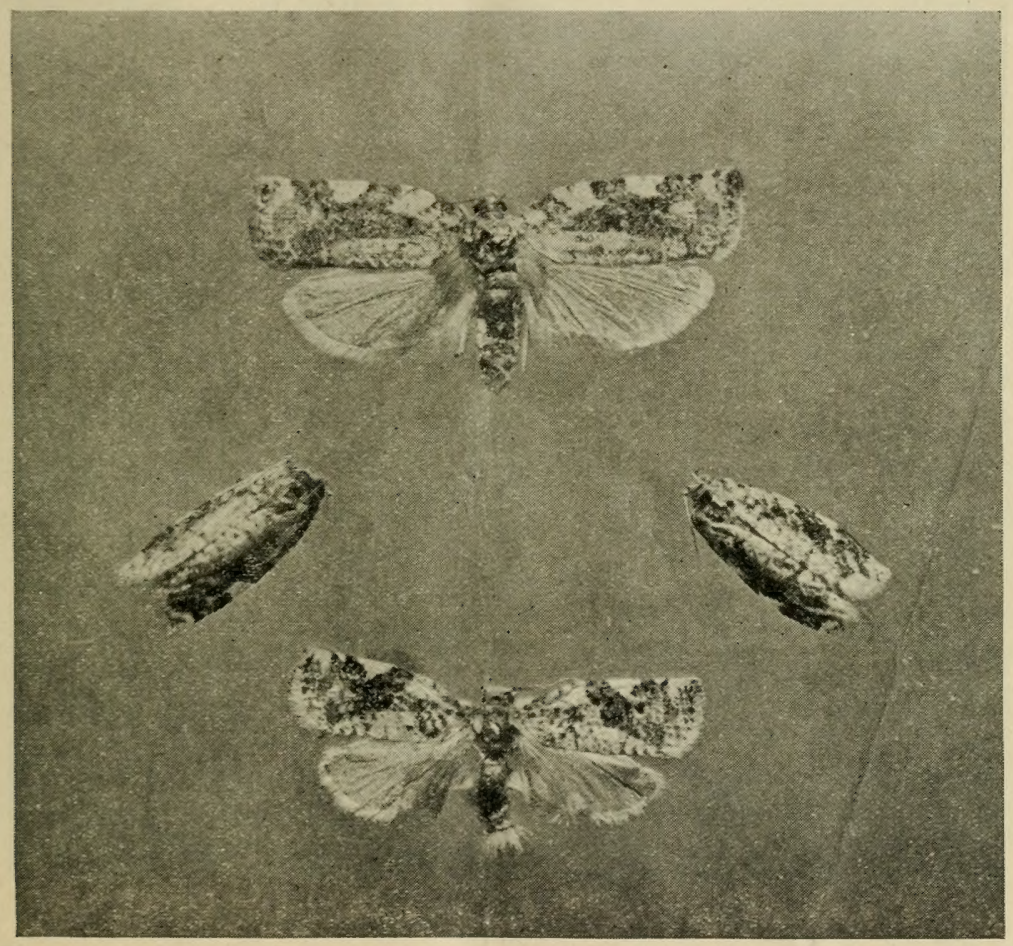

FIG. 1.

Adults of the Fruit Tree Leaf Roller: female above, in center; male, below.

Slightly enlarged. The front wings are mottled with white and brown markings; hind wings, ash-gray.

known to occur in Illinois for many years, and in the western states, particularly in Oregon, Washington, Idaho, and Colorado, it has for the last ten or fifteen years been one of the most destructive of the insects infesting the apple.

* Archips argyrospila Walk 
During the past few seasons it has become a serious pest in some of our western Illinois apple-orchards, and it is apparently on the increase thruout the orchards of this section of the state. While the area of serious infestation and destructiveness of this pest has been somewhat limited, the damage from it in this area has been so severe as to warrant special work on control under Illinois conditions. The experiments here reported were started in 1924 and continued thru 1925. While they have

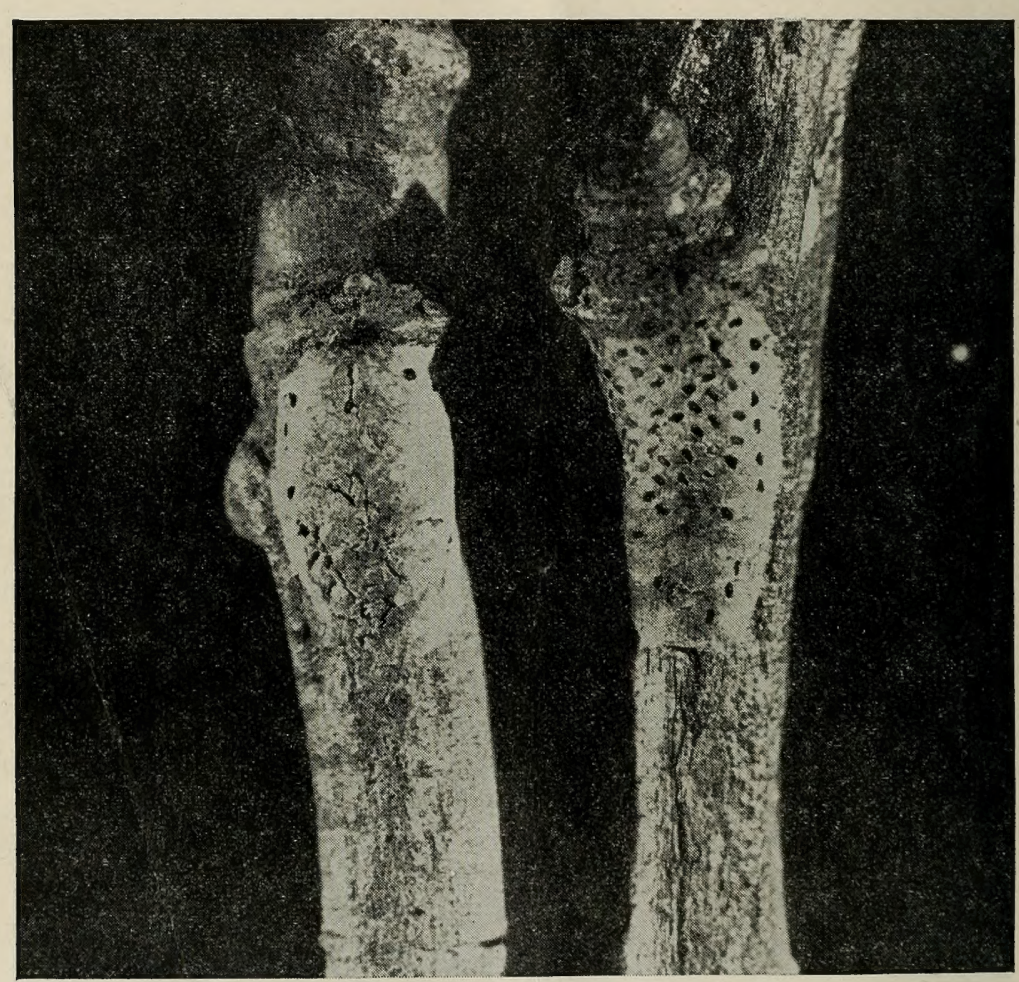

Fig. 2.

Egg masses of the Fruit Tree Leaf Roller attached to the bark of small twigs. The holes in the coating over the eggs show where the worms have hatched.

covered only two seasons, they were numerous enough and their results were consistent enough to warrant final conclusions, especially as these are in accord with those arrived at in some of the far-western states.

The life history of the fruit tree leaf roller in Illinois is essentially the same in all parts of the state. The insect passes the winter in the egg stage. The eggs are laid in masses of from 50 to 150 , closely plastered 
on the twigs and branches and occasionally on the trunk of the tree. They are covered with a smooth, gummy, grayish brown substance, and blend almost perfectly with the bark on which they are deposited, making it extremely difficult to see them. The egg masses are from a quarter to nearly a half inch in length, and about half as wide as long. The eggs begin hatching about the time the apple fruit-buds are separating in the spring, or at the early cluster bud stage of the apple. The small blackish worms crawl from the egg mass to the young leaves and spin a light

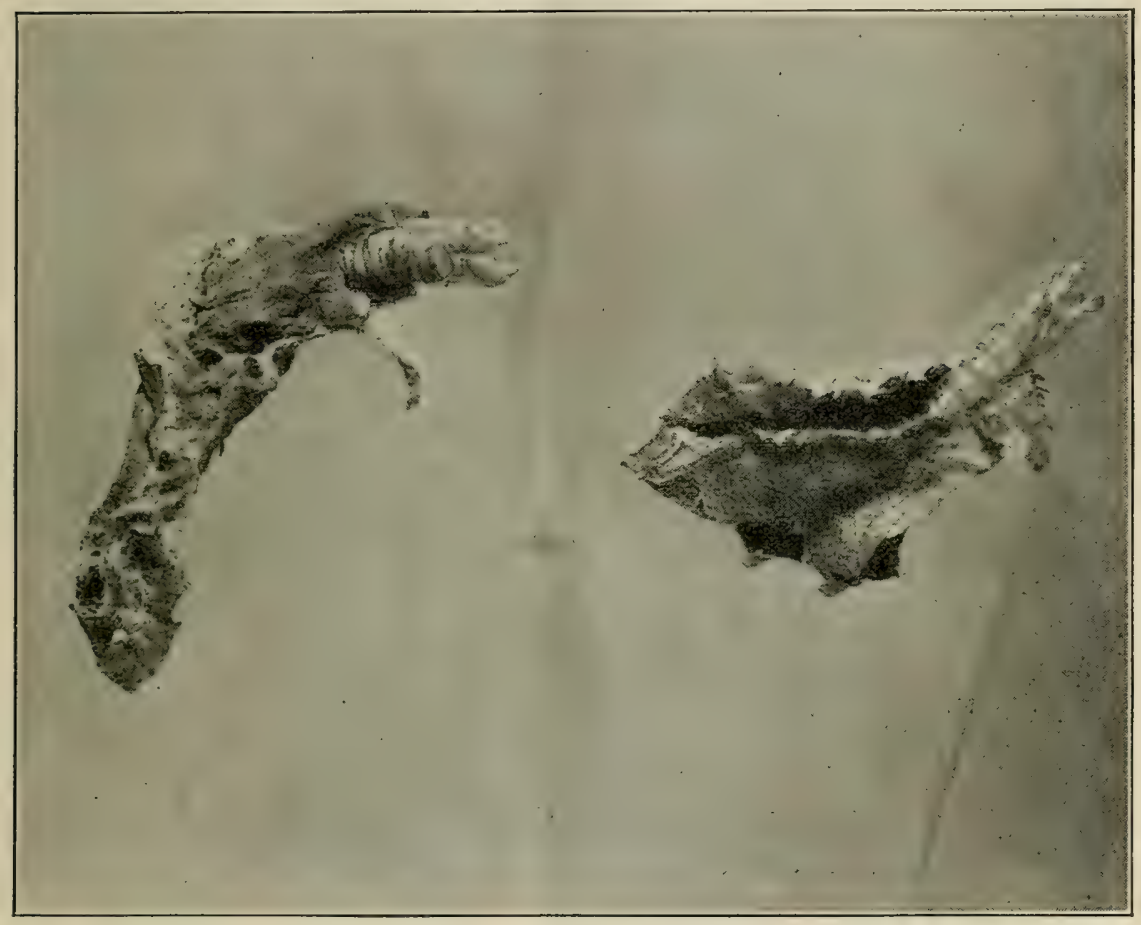

FIG. 3.

Cocoons of the Fruit Tree Leaf Roller in crumpled leaves with empty pupa-cases protruding from them.

web over the leaves and buds, drawing or rolling them together. They begin feeding within this lightly webbed enclosure, and as soon as the blossoms have opened and the young apples have set, they eat out cavities in the sides of the apple, doing an injury somewhat like that done by the green fruit worm. The young worms vary somewhat in color, but when full grown they are, in general, about three-fourths of an inch in length, pale green, and without special markings except for a brown 


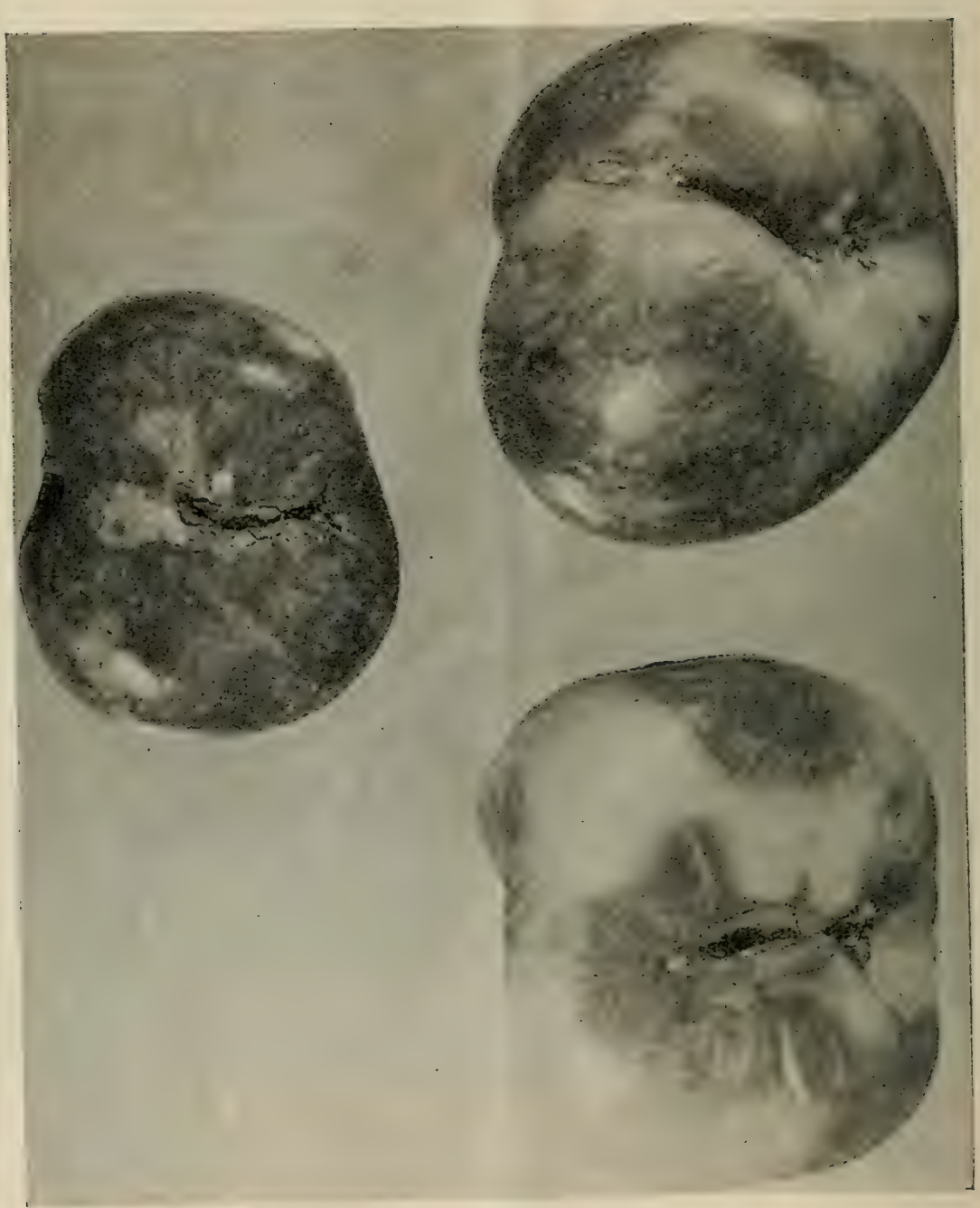

FIG. 4.

Apples bearing typical Leaf Roller scars at time of picking. The injury was caused by the feeding of the caterpillars during the first two weeks after the fruit had set. 
head and a palc brown shield just back of it. They change to a brown pupal stage within a light cocoon in the webbed leaves or, occasionally, on the trunk or branches of the tree. The adult moths emerge from this cocoon during late June or July.

They are about half an inch long when the wings are folded, and the fore wings are brownish with irregular light markings. Soon after emerging from the cocoon the females mate and deposit their eggs, as just described. They die shortly after egg-laying, and the insect remains in the egg stage until the following spring.

As the larvae have chewing mouth parts, it might be supposed that they could be easily killed by a poison spray applied to the leaves and young fruit, but experiments in this and other states have shown that this is not the case, since it is almost impossible to force through the webs enclosing the leaves poison spray enough to kill the young worms.

Because of a marked increase in the numbers of the leaf roller larvae during the spring of 1924 , an attempt was made to control the pest by an arsenical spray, but the usual spray of 1 pound of arsenate of lead to 100 gallons of water, as applied for the codling moth, had practically no effect on the leaf roller. A spray of 4 pounds of powdered lead arsenate and a pound of Paris green to each 100 gallons of water was tried on the apple trees of some 100 acres in the most seriously infested orchard. An examination of the orchard a week later showed that only 10 to $25 \%$ of the leaf roller larvae had been killed, even though a special effort had been made to drive the spray into the webbed leaves and buds.

Our Illinois experiments for the control of the leaf roller in the egg or winter stage have followed closely the methods found most effective against this insect in the western states, but nothing had previously been done with a lubricating oil emulsion like that most effective against the San Jose scale in Illinois. Since our work was finished, experinents made in Washington with the same type of oil emulsion and of the same strength have given very good control in that state.

In the winter of 1924-25, a series of experiments was carried on in our most heavily infested orchard to test the effect of different commercial miscible oils and of several strengths and grades of lubricating oil emulsion on the overwintering eggs of the leaf roller. Three brands of commercial miscible oils or oil emulsions were used, and also lubricating oil emulsions of light and heavy oils at $4 \%$ and $8 \%$ strengths, made by both the boiled and cold-mixed formulae.* The formula found effective by Dr. Melander for use against leaf roller eggs in Washington was also tried at \pm and $8 \%$ strength. $\dagger$ Considerable difficulty was experienced in making a stable emulsion from this formula and the poor results from its use were probably due to this fact The commercial miscible oils were used at strengths of 1 part to $2 \pm$ parts of water, and 1 part to $12 \mathrm{I} / 2$ parts of water. The treatments were first begun on November 28, and continued to December 8 as the weather permitted. A number of infested twigs containing many egg masses were taken from the

* All the oils used, were oils with a paraffin base.

$\dagger$ Bul. 184, Wash. Agr. Exper. Station. 1924. 
TABIE I

Treatment

No. 1. Cold-mixed calcium caseinate oil emulsion. Oil of 90 viscosity. Used at $4 \%$ strength

No. 2. Same as No. 1. Used at $8 \%$ strength

No. 3. Cold-mixed calcium caseinate oil emulsion. Oil of 200 viscosity. Used at $4 \%$ strength

No 4. Same as No. 3. Used at $8 \%$ strength

No. 5. Melander's formula, using homemade miscible oil: lubricating oil, 200 viscosity, 91\%; emulsifier, $9 \%$. Used at $4 \%$ strength

No. 6. Same as No. 5. Used at $8 \%$ strength

No. 7. Glue emulsion made according to Melander's formula: 50 gallons of oil of 200 viscosity, $16 \frac{1}{2}$ gallons of water, and 2 pounds of glue. Used at $4 \%$ strength

No. 8. Same as No. 7. Used at $8 \%$ strength

No. 9. B o iled lubricating oil emulsion made by Illinois formula: 1 gallon oil, 2 pounds potash fish-oil soap, $1 / 4$ gallon water. Oil of 90 viscosity. Used at $4 \%$ strength

No. 10. Same as No. 9. Used at $8 \%$ strength

No. 11. Same as-No. 9, except oil of 200 viscosity. Used at $4 \%$ strength

No. 12. Same as No. 11. Used at $8 \%$ strength

No. 13. Cold-mixed Bordeaux oil emulsion, using 4-6-50 Bordeaux (hydrated lime) diluted with $1 / 4-1 / 2-50$ Bordeaux. Used at $4 \%$ strength. Oil of 200 viscosity.

No. 14. Same as No. 13. Used at $8 \%$ strength

No. 15. Sherwin-Williams' "Freemulsion," 1 to 24 parts water

No. 16. Same as No. 15, 1 to $12 \frac{1 / 2}{\text { parts }}$ water

No.17. "Sunoso" oil emulsion, 1 to 24 parts water

No. 18. Same as No. 17, 1 to $12 \frac{1 / 2}{\text { parts }}$ water

No. 19. Standard Oil No. 3290 emulsion, 1 to 24 parts water

No. 20. Same as No. 19,1 to $121 / 2$ parts water

No. 21. Untreated check

No. 22. Untreated check

\begin{tabular}{|c|c|c|c|c|}
\hline $\begin{array}{l}\text { No. of } \\
\text { tests }\end{array}$ & $\begin{array}{l}\text { No. of } \\
\text { egg } \\
\text { masses } \\
\text { under } \\
\text { obser- } \\
\text { vation }\end{array}$ & $\begin{array}{l}\text { Per cent } \\
\text { of egg } \\
\text { masses } \\
\text { from } \\
\text { which } \\
\text { larvae } \\
\text { hatched }\end{array}$ & $\begin{array}{c}\text { Total } \\
\text { No. of } \\
\text { larvae } \\
\text { hatched }\end{array}$ & $\begin{array}{c}\text { Average } \\
\text { No. of } \\
\text { larvae } \\
\text { per egg } \\
\text { mass }\end{array}$ \\
\hline 4 & 75 & 12 & 167 & 2.2 \\
\hline 4 & 73 & 1.2 & 20 & 0.2 \\
\hline 4 & 77 & 0 & & \\
\hline 4 & 63 & 0 & & \\
\hline 3 & 77 & 52 & 1378 & 18 \\
\hline 3 & 70 & 49 & 1681 & 24 \\
\hline 3 & 68 & 2.9 & 128 & 1.8 \\
\hline 3 & 70 & 0 & 0 & 0 \\
\hline 4 & 68 & 24.4 & 237 & 3.4 \\
\hline 4 & 61 & 8.1 & 14 & 0.2 \\
\hline 4 & 65 & 28.6 & 625 & 9.6 \\
\hline 4 & 66 & 1.5 & 7 & 0.1 \\
\hline 4 & 72 & 38.8 & 1502 & 20.8 \\
\hline 4 & 73 & 0 & & \\
\hline 3 & 36 & 52.7 & 340 & 9.4 \\
\hline 3 & 35 & 40 & 235 & 6.7 \\
\hline 3 & 70 & 50 & 933 & 13.3 \\
\hline 3 & 64 & 32.6 & 518 & 8 \\
\hline 4 & 69 & 43.5 & 1059 & $15 . ?$ \\
\hline 4 & 61 & 29.5 & 520 & 8.3 \\
\hline 4 & 85 & 71.7 & 1986 & 23.2 \\
\hline 4 & 63 & 65 & 1597 & 24.5 \\
\hline
\end{tabular}


trees about a week after treating, removed to a greenhouse, and kept in large test-tubes on moist sand at temperatures of from $50^{\circ}$ to $35^{\circ} \mathrm{F}$. until all hatching had stopped. Another lot of twigs was removed from the same plots in March and also kept in the greenhouse where accurate observation on the hatch of eggs could be made. Another set of plots was treated in the orchard the middle of March. Infested twigs were removed the latter part of the month and kept under observation, and a smaller lot of egg masses was treated in the laboratory and removed to the greenhouse for hatching. The results of these various treatments are given in the preceding table. There were no significant differences in the hatch of eggs which had received late fall or early spring treatments.

It will be noticed by a study of the table, that the $8 \%$ lubricating oil emulsion made with either light or heavy oils, and either cold-mixed or boiled, gave a very satisfactory degree of control of the leaf roller eggs, the per cent of hatch being lower than that resulting from any of the treatments with the commercial oil emulsions or miscible oils used.

The owner of the worst infested orchard treated about 1000 acres of mature apple trees with the boiled lubricating oil emulsion, using an oil of about 90 viscosity at $8 \%$ strength in the diluted emulsion. Spraying was started about December 8 and continued until the first of April, many periods of cold stormy weather making it impossible to apply the spray to the entire acreage before this time.

Egg masses of the leaf roller thus sprayed were removed at intervals during the winter, and kept under observation in the greenhouse so that accurate data on the hatch could be obtained. The results of these observations are given in the following table:

TABLE II

\begin{tabular}{l|c|c|c}
\hline \hline Treatment & $\begin{array}{c}\text { Number of } \\
\text { egg masses } \\
\text { under } \\
\text { observation }\end{array}$ & $\begin{array}{c}\text { Number of } \\
\text { egg masses } \\
\text { from which } \\
\text { larvae } \\
\text { hatched }\end{array}$ & $\begin{array}{r}\text { Total } \\
\text { larvae } \\
\text { hatched }\end{array}$ \\
\hline $\begin{array}{l}\text { Spraying by the orchard owner with 8\% } \\
\text { boiled lubricating oil emulsion. Oil } 90 \\
\text { viscosity }\end{array}$ & $85^{*}$ & 4 & $87 \dagger$ \\
\hline Untreated check & 48 & & 935
\end{tabular}

* These egg masses were taken at random, two or three from a tree in different parts of the orchard.

† Seventy-nine of these larvae hatched from a single egg mass which had apparently not been hit by the spray. 
The orchard was carefully exanined in the spring at a time when the leaf roller larvae were nearly full grown, and it was very difficult to find any of the worms in the orchard. An examination of 5000 apples made in late July in parts of the orchard which had been most heavily infested the previous year, showed that the damage to the fruit had been reduced from approximately $50 \%$ of the entire crop in 1924 to $2 \%$ in 1925. As to the effect on the trees from extremely heavy applications of the $8 \%$ oil emulsion, no injurious effect whatsoever was noticed on any of the varieties, including Kennard, Grimes Golden, Jonathan, Huntsman, Maiden Blush, Wealthy, Ben Davis, Willow Twig, Missouri Pippin. and several others. The crop borne was one of the largest in the history of the orchard, and no injury to the trees, bark, foliage, or fruit could be seen. The same strength of oil spray was used in several other orchards without any injury to the trees. The hatch of the check plots and the number of eggs present in the orchards when the treatment was given, make it practically certain that had no treatment been applied the injury would have been more serious in 1925 than in 1924 . While only one year's experimental results are reported, enough egg masses were treated under varying weather conditions at different times during the dormant season to make it seem certain that a treatment with an $8 \%$ boiled lubricating oil emulsion, made with paraffin oils of from 90 to 200 viscosity, of the grade usually employed for lubricating slow-moving bearings, can be depended upon to kill the eggs of the fruit tree leaf roller and clean up infestations of this insect even in very heavily infested orchards.

Because of the difficulty under local conditions in making cold-mixed emulsions that will hold up well when not used for several days, the boiled lubricating oil enulsion is recommended in Illinois for the control of this pest.

\section{Directions for Making Boiled Lubricating Oil Emulsion}

The equipment necessary for making the boiled lubricating oil emulsion consists of a cooking tank of 50 to 500 gallons capacity-a 200 to 400 gallon tank is preferable when large amounts of the emulsion are to be made- a steam boiler capable of producing from 20 to 40 pounds steam pressure, a second tank of equal capacity to the first, and a pump capable of developing 100 to 200 pounds pressure. A steam coil should be rum from the boiler to and around the bottom of the cooking tank. One-sixteenth to one-eighth inch holes should be made in this coil at frequent intervals to allow the escape of the steam into the liquid in the cooker. The second tank should be so adapted that the liquid from the cooking tank can be run thru the pump into the second tank and then back thru the pump into barrels or other containers to be used for storage. The formula which has been found best under Illinois conditions is as follows: 
Light grade lubricating oil*........1 gallon

Water $\ldots \ldots \ldots \ldots \ldots \ldots \ldots \ldots \ldots \ldots \ldots$. $1 / 4$ gallon

Potash fish-oil soap..............1 to 2 pounds

(Many waters require more than one pound of soap to stabilize the emulsion.)

Place the water, soap, and oil in a kettle or tank heated by fire or steam. Boil for five minutes, being careful, if fire is used, not to burn the mixture. Remove from the fire or turn off the steam and pump twice thru a spray pump at a pressure of 100 to 200 pounds. Make sure that all the mixture passes thru the pump twice. Do not allow it to cool before pumping.

For making the stock emulsion on a large scale, an all-metal pump is necessary. The rotary type has been found fairly satisfactory for this work, but a good steam pump is better. For small amounts, a barrel pump may be used. The stock emulsion should not be used in a cooker which has previously been used for cooking lime-sulphur without a thorough cleaning, nor should it be stored in lime-sulphur barrels.

Precaution should be taken to prevent the stock emulsion from freezing. If it does freeze it should be allowed to thaw out gradually, under which circumstances apparently no harm results to the emulsion. Do not raise to high temperature or stir while the emtnlsion is thawing out.

For spraying the leaf roller eggs use twelve gallons of the emulsion made by the preceding formula in eighty-eight gallons of water. When spraying for San Jose scale use three gallons of the same emulsion in ninety-seven gallons of water.

Spray tanks which have been used for lime-sulphur solution must not be used for oil emulsion until they have been washed out with Bordeaux mixture. To wash a tank with Bordeaux, 8 pounds of hydrated lime or 6 pounds of freshly slacked lump lime should be mixed with about 100 gallons of water in the tank, and a solution containing 4 pounds of copper sulfate should be poured in while the agitator is running. When the inside of the tank has been thoroughly splashed and soaked with the solution, a few gallons should be run thru the pump and hose and the tank drained. A strong lye solution can also be used.

\section{Calcium Caseinate Emulsion}

For making the cold-mixed calcium caseinate emulsion no cooking tank is necessary, the only equipment needed being several barrels or casks for storing the emulsion and a pump which will develop from 100 to 200 pounds pressure. The same grades of oil can be used for the calcium caseinate emulsion as for the boiled lubricating oil emulsion.

* The best results have been obtained with oils within the following specifications:

Specific gravity at $20^{\circ}$ C....... 0.87 to 0.93

Volatility at $110^{\circ} \mathrm{C}$. for 4 hours. not above 2 per cent

Viscosity at $100^{\circ}$ F..............90 to 250 seconds (Saybold test) 
The formula for making this emulsion is as follows:

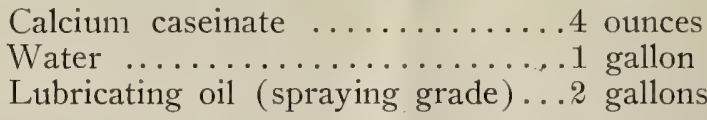

The calcium caseinate is first thoroughly mixed with the water, then the oil is added and the whole is run thru the pump at least twice. This emulsion should be prepared as needed, as it will usually break down on standing for two or three days. If this happens, it should be thoroughly repumped before being diluted in the spray tank. Cold-mixed oil emulsions may also be made with several other emulsifiers, including 4-4-50 Bordeaux mixture used at the rate of one gallon of the Bordeaux mixture to one gallon of the lubricating oil, the two being thoroughly pumped and diluted in very weak Bordeaux made at the rate of one-half pound of copper sulfate and one-half pound of lime to fifty gallons of water. If diluted with clear water, this mixture will have a tendency to rise to the top of the tank. Several other emulsifiers, including certain clays and other colloidal substances, can be used in making oil emulsion.

For further information in regard to these spraying materials or the fruit tree leaf roller, write the Natural History Survey, Urbana, Illinois. 




$$
\text { . }
$$




UNIVERSITY OF ILLINOIS-URBANA

570IL6C

CIRCULAR C006

1-24

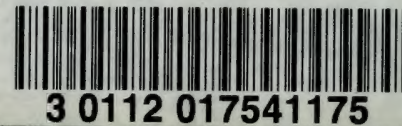

